\title{
THE EFFECTS OF EATING HABITS, PHYSICAL ACTIVITY, NUTRITION KNOWLEDGE AND SELF-EFFICACY LEVELS ON OBESITY
}

\author{
Pervin TOPTAŞ DEMİRCI ${ }^{1}$, Nevzat DEMİRC $\dot{I}^{1}$, Erdal DEMİRCI $^{3}$ \\ ${ }^{1}$ Mersin University Department of Tourism Animation, Mersin/Turkey \\ ${ }^{2}$ Mersin University, Physical Education and Sport Sciences, Mersin/Turkey \\ ${ }^{3}$ Kafkas University, Physical Education and Sport Sciences, Kars/Turkey
}

\begin{abstract}
Objective: The purpose of this study is investigate the effects of eating habits, physical activity, nutrition knowledge and self-efficacy levels on obesity

Methods: The participants of the research were Kafkas University Physical Education and Sports College and Sarıamıs Vocational School students. Research includes eating habits, physical activity (PA), nutrition knowledge and self-efficacy questionnaire. The cases were divided into normal weight $(\mathrm{NW})$ and overweight - obese (OW) groups based on age, sex, body mass index percentages. The obtained data were analyzed using SPSS.

Results: Approximately 35.5\% of participants were identified as overweight or obese. Significant differences were observed between the $O W$ and NW groups in terms of gender, weight control interest $(P<0.01)$. OW group women were found to exhibit less desirable behaviors when compared to NW. Compared to OW group NW group, it was determined that women participated in less physical activity than men. There was no significant difference in nutritional information between $O W$ and $N W$ groups. In particular, the self-efficacy level of the PA was significantly lower in the OW group than in the NW group $(P<0.01)$.

Conclusion: This study reveals eating habits, PA and self-efficacy differences among university students. It should focus on improving the self-efficacy of university students, changing eating habits and increasing PA levels by organizing programs to combat obesity.
\end{abstract}

Key Words: Student, obesity, weight control, physical activity, nutrition knowledge

\section{Introduction}

According to the World Health Organization (WHO) report, the prevalence of obesity doubled worldwide between 1980 and 2014 (Seong et al., 2016). Many countries have embraced and implemented various national policies to prevent obesity and to reduce obesity and socio-economic burden, since obesity has been shown to be a risk factor for chronic diseases such as cardiovascular disease, type II diabetes and some cancers (Brown et al., 1998). Throughout the period corresponding to early adulthood in college, social and emotional development is complemented by physical maturity and one's eating habits are determined (Yu et al., 2014).

However, the increasing risk of chronic illness due to changes in nutrition habits by university students is not adequately considered. Obesity in college students is seen as the first indication of the risk of future chronic diseases of obesity (Keihner et al., 2011). For this reason, it is very important to actively control obesity from the first years of university. Although the cause of obesity is complicated, nutrition habits or lifestyle play an important role in the development of obese conditions (Hatfield et al., 2015; Lee et al., 2014). The aim of this study is to examine the eating habits, physical activities, nutrition knowledge and self-sufficiency of university students and to investigate whether these characteristics differ according to obesity status.

\section{Material and method \\ Subject and Participants}

Participants of this study were students from the faculty and college of Kafkas University. The criteria for inclusion in the study are university students over the age of 18 , no chronic illness, no chronic drug use, no musculoskeletal problems that could affect physical activity. The study includes nutrition habits, physical activity (PA), nutrition knowledge and self-efficacy levels in university students. All students participated in volunteer work, and each student was informed about the study prior to the application and taken to participate in the "Informed Consent Form" in accordance with Helsinki (WMADH, 2000). 220 male and female healthy university students participated in the study. Par- 
ticipants were divided into two groups, normal weight (NW) and overweight-obese (OW), based on age, sex, and body mass index percentages.

\section{Procedures}

The study questionnaire was based on university students' eating habits, physical activity and nutrition knowledge, and literature review to determine self-efficacy levels (Ha et al., 2016; Cho et al., 2009; Kang 2009). General features include age, gender, height, weight, body mass index (BMI) items. The body mass index was calculated based on the weight and the dye reported. Participants' height measurements were measured by the millimetric height scale and body weight measurements by electronic scales. Body weight and height measurements are formulated by adding them to personal information forms. BMI = Body Weight $(\mathrm{kg}) /$ Boy2 $(\mathrm{m})$. BMI values were obtained by dividing the body length by body weight after taking the length of the body length. Overweight-obese (OW) with $\mathrm{BMI} \geq 25$ and $\mathrm{BMI} 18.5<\mathrm{BKI}<25$ were determined as those with normal weight (NW).

\section{Data Collection Tools \\ Eating Habits}

Eating habits included diverse foods, regular meals, size of food, frequency of breakfast meals, eating and snacks, behavior during meals, unbalanced diet and unfavorable food (Na et al., 2010; Choi \& Seo., 2003). These variables were measured using 5-point scales or by asking them to record the frequency of their behavior or to check the categories.

\section{Physical Activity}

Physical activity is measured based on seven factors: the frequency of physical activity for at least 30 minutes per day, the frequency of walking or cycling, the frequency of exercise, weekday or weekend walking times, weekday or weekly moving time, by the number of activities it has performed (Guthold et al., 2010; Centers for Disease Control and Prevention, 2007). The time spent walking was measured using four categories: "less than $30 \mathrm{~min}$ utes a day" or "more than 2 hours a day." The inactive time spent was measured using the categories "from less than one hour a day" to "no more than 4 hours a day"

\section{Nutrition Knowledge}

Nutrition information was measured on 10 items, including general nutrition (six items) and infor- mation about obesity (four items) ( $\mathrm{Na}$ et al., 2010; Choi \& Seo, 2003). Information about obesity, definition of obesity, adequate weight control, fruit and energy and the effects of regular exercise. For each nutritional information item, the number and percentage of correct answers of the subjects were examined. The total score of the nutrition knowledge was the total score of the correct answers for the 10 nutrition information items.

\section{Self-Efficacy}

Self-efficacy obesity status in eating or physical activity was assessed using 10 items ( $\mathrm{Na}$ et al., 2010; Ko \& Kim, 2010; Kang 2009). Self-efficacy in physical activity was measured using four items. They regularly participate in spore exercises, perceived efficacy on tired or bad weather conditions, driving at short distances, exercising at lunch or in the malls. Each item was measured on a 4 -item scale between 'very difficult' (1) and 'very easy' (4). The total score for self-efficacy was calculated as a total of 10 item points.

\section{Statistical analyzes}

SPSS (PASW Statistics 18.0; SPSS Inc., Chicago, IL, USA). Descriptive statistics including frequency, percentages, mean and standard deviation were calculated. Body weight and height measurements are formulated by adding them to personal information forms. BMI = Body Weight $(\mathrm{kg}) /$ Boy2 (m). BMI values were obtained by dividing the body length by body length after taking the body length. The T-test was used to examine the differences between the eating habits, physical activity, nutrition knowledge and self-efficacy according to obesity status. Statistical significance was examined at $\mathrm{P}<0.05$.

\section{Results}

Participants were found to have an average age of 21.97 and approximately $64.5 \%$ (142) for the normal weight (NA) group and $35.5 \%$ (78) for overweight - obesity (OW). Gender is significantly different according to obesity status; In the OW group, the rate of famale $(64.1 \%)$ was higher than that of the NW group $(56.3 \%, \mathrm{P}<0.01)$ (Table 1$)$. 
Table 1: General Descriptive Characteristics of University Students

\begin{tabular}{llll}
\hline & \multicolumn{3}{l}{ Obesity status $^{1}$} \\
Variables & $\begin{array}{l}\text { Normal } \\
(\mathrm{n}=142)\end{array}$ & $\begin{array}{l}\text { Overweight \& Obesity } \\
(\mathrm{n}=78)\end{array}$ & $\begin{array}{l}\text { Total } \\
(\mathrm{n}=220)\end{array}$ \\
Age & $22.0 \pm 1.7$ & $21.95 \pm 2.2^{2)}$ & $21.97 \pm 1.95$ \\
Weight & $66.4 \pm$ & & \\
$(\mathrm{kg})$ & 14.8 & $78.5 \pm 11.8$ & $72.45 \pm 13.3$ \\
Height & $175.0 \pm$ & $169.0 \pm 10.1$ & $172 \pm 10.2$ \\
$(\mathrm{~cm})$ & 10.3 & $28.2 \pm 3.4$ & $25.4 \pm 3.7$ \\
BMI & $22.6 \pm 4.128(35.9)$ & $90(39.8)$ \\
Male & $62(43.7)$ & \\
\hline Famale & $80(56.3)$ & $50(64.1)^{3) * *}$ & $130(60.2)$ \\
\hline
\end{tabular}

$\left.{ }^{* *} \mathrm{P}<0.01,{ }^{1}\right) \mathrm{BKI} \geq 25$ olan aşırı kilolu- Obez (OW) ve BKİ $18.5<$ BKİ $<25$ arası normal ağırlıkta (NW) $\left.{ }^{2}\right)$ Mean $\left.\pm \mathrm{SD},{ }^{3}\right) \mathrm{n}(\%)$
The average frequency of breakfast was $5.0 \pm 1.6$ and the frequency of breakfast in both sexes was lower than in the NW group $(\mathrm{P}<0.05)$. While the frequency of eating outside did not differ from that of obesity in men, OW women eat less than women $(\mathrm{P}<0.01)$. Approximately $34 \%$ of participants were fed with irregular food, while the rate of regular eating was about $35 \%$. The proportion of 'small' or 'very small' respondents according to the size of the meal ratio was significantly higher in the OW group $(\mathrm{P}<0.001)$ compared to the NW group in both boys and girls. The proportion of women fed an unbalanced diet was $41.2 \%$ lower in the OW group $(36.0 \%)$ than in the NW group $(\mathrm{P}<0.001)$. There was no significant difference between the participants regarding the unfavorable foods (Table 2).

Table 2: Eating habits according to obesity status in university students

\begin{tabular}{|c|c|c|c|c|c|}
\hline \multirow[t]{2}{*}{ Variables } & \multicolumn{2}{|r|}{ Male $(n=90)$} & \multicolumn{2}{|c|}{ Famale $(n=130)$} & \multirow[b]{2}{*}{$\begin{array}{c}\text { Total } \\
(\mathrm{n}=220)\end{array}$} \\
\hline & $\begin{array}{l}\text { Normal } \\
(\mathrm{n}=62)\end{array}$ & $\begin{array}{l}\text { Overweight \& Obesity } \\
(\mathrm{n}=28)\end{array}$ & $\begin{array}{l}\text { Normal } \\
(\mathrm{n}=80)\end{array}$ & $\begin{array}{l}\text { Overweight \& Obesity } \\
\qquad(\mathrm{n}=50)\end{array}$ & \\
\hline Breakfast frequency (times/week) & $5.6 \pm 1.4$ & $4.5 \pm 1.6^{3)^{*}}$ & $5.7 \pm 1.6$ & $4.4 \pm 1.7^{*}$ & $5.0 \pm 1.6$ \\
\hline Frequency of eating out (times/week) & $1.3 \pm 1.1$ & $1.1 \pm 0.8$ & $1.4 \pm 0.7$ & $1.1 \pm 0.8^{\star \star}$ & $1.2 \pm 0.8$ \\
\hline $\begin{array}{l}\text { Frequency of eating snacks (times/ } \\
\text { day) }\end{array}$ & $1.6 \pm 1.3$ & $1.2 \pm 0.8^{\star *}$ & $1.6 \pm 1.2$ & $1.2 \pm 0.8^{\star *}$ & $1.4 \pm 1.0$ \\
\hline \multicolumn{6}{|l|}{ Variety of foods } \\
\hline Do not eat a variety of foods at all & $7(11.3)$ & $3(10.7)^{4) \star}$ & $11(13.7)$ & $4(8.0)^{\star}$ & $25(11.4)$ \\
\hline Do not eat a variety of foods & $8(12.9)$ & $5(17.9)$ & $13(16.3)$ & $9(18.0)$ & $35(15.9)$ \\
\hline Average & $17(27.4)$ & $7(25.0)$ & $26(32.5)$ & $14(28.0)$ & $64(29.0)$ \\
\hline Eat a variety of foods & $16(25.8)$ & $8(28.5)$ & $18(22.5)$ & $13(26.0)$ & $55(25.0)$ \\
\hline \multirow{2}{*}{\multicolumn{6}{|c|}{ Regular meals }} \\
\hline & & & & & \\
\hline Very irregular & $6(9.7)$ & $4(14.3)$ & $9(11.2)$ & $8(16.0)^{* *}$ & $27(12.3)$ \\
\hline Irregular & $12(19.3)$ & $6(21.5)$ & $18(22.5)$ & $12(24.0)$ & $48(21.8$ \\
\hline Neither irregular nor regular & $17(27.4)$ & $8(28.5)$ & $25(31.3)$ & $16(32.0)$ & $64(29.0)$ \\
\hline Regular & $18(29.0)$ & $7(25.0)$ & $20(25.0)$ & $9(18.0)$ & $54(24.5)$ \\
\hline Very regular & $9(14.6)$ & $3(10.7)$ & $8(10.0)$ & $5(10.0)$ & 25(11.4) \\
\hline \multicolumn{6}{|l|}{ Size of meals } \\
\hline Very small/ small & $18(29.0)$ & $5(17.9)^{\star *}$ & $15(18.7)$ & $17(34.0)^{* *}$ & $55(25.0)$ \\
\hline Adequate & $24(38.7)$ & $16(57.1)$ & $43(53.8)$ & $23(46.0)$ & $106(48.1)$ \\
\hline Large/very large & $20(32.3)$ & $7(25.0)$ & $22(27.5)$ & $10(20.0)$ & $59(26.9)$ \\
\hline \multicolumn{6}{|l|}{ Behavior during meals } \\
\hline Just eating & $15(24.1)$ & $7(25.0)$ & $12(15.0)$ & $7(14.0)$ & $41(18.6)$ \\
\hline Conversation with family members & $25(40.3)$ & $13(46.4)$ & $48(60.0)$ & $25(50.0)$ & $111(50.5)$ \\
\hline Playing games or watching TV & $13(20.9)$ & $5(17.9)$ & $13(16.3)$ & $10(20.0)$ & 41(18.6) \\
\hline Reading a book or others & $9(14.7)$ & $3(10.7)$ & $7(8.7)$ & $8(16.0)$ & $27(12.3)$ \\
\hline \multicolumn{6}{|l|}{ Unbalanced diet } \\
\hline Yes & $25(40.3)$ & $10(35.7)$ & $33(41.2)$ & $18(36.0)^{\star *}$ & $86(39.1)$ \\
\hline No & $37(59.7)$ & $18(64.3)$ & $47(58.8)$ & $32(64.0)$ & $134(60.9)$ \\
\hline \multicolumn{6}{|l|}{ Foods that they dislike ${ }^{1)}$} \\
\hline Grains and starches & $11(17.7)^{5)}$ & $8(28.4)$ & $16(20.0)$ & $12(24.0)$ & $47(21.4)$ \\
\hline Meat & $7(11.3)$ & $3(10.7)$ & $11(13.7)$ & $8(16.0)$ & $29(13.2)$ \\
\hline Fish & $3(4.8)$ & $2(7.2)$ & $5(6.3)$ & $4(8.0)$ & $14(6.3)$ \\
\hline Eggs & $6(9.7)$ & $2(7.2)$ & $8(10.0)$ & $5(10.0)$ & 21(9.5) \\
\hline Beans & $11(17.7)$ & $3(10.7)$ & $13(16.3)$ & $7(14.0)$ & $34(15.5)$ \\
\hline Vegetables & $8(12.9)$ & $2(7.2)$ & $7(8.7)$ & $5(10.0)$ & $22(10.0$ \\
\hline Fruits & $6(9.7)$ & $3(10.7)$ & $6(7.5)$ & $4(8.0)$ & 19(8.6) \\
\hline Dairy products & $4(6.5)$ & $3(10.7)$ & $5(6.3)$ & $3(6.0)$ & $15(6.9)$ \\
\hline Seaweeds & 0 & 0 & 0 & 0 & 0 \\
\hline Others ${ }^{2)}$ & $6(9.7)$ & $2(7.2)$ & $9(11.2)$ & $2(4.0)$ & $19(8.6)$ \\
\hline
\end{tabular}

$\left.{ }^{\star} \mathrm{P}<0.05,{ }^{*} \mathrm{P}<0.01,1\right)$ Multiple answers, 2) Shellfish, soy bean paste, greasy foods, spicy foods, etc. 3) Mean \pm SD4) $\mathrm{n}(\%), 5)$ The number in parentheses is the percentage of total subjects in each group. 
Physical activity variables in women and men were significantly different between OW and NW groups. The percentage of those who stated that they did not walk or bike on weekends were higher in male OW and female OW groups $(\mathrm{P}<0.05)$. OW $71.5 \%$ of males and $76 \%$ of females were less than 3 hours per day during the weekend, $28.7 \%$ of NW females performed more than 3 hours at the week- end $(\mathrm{P}<0.01)$. Approximately $30 \%$ of $\mathrm{OW}$ women participated in physical activity for at least $30 \mathrm{~min}$ utes a day. The proportion of OW women exercising three or more times per week was lower than NW women $(\mathrm{P}<0.01)$. Approximately $90 \%$ of OW women walked less than an hour during weekdays or weekends, which was significantly higher than NW men (weekday and weekend $\mathrm{p}<0.01$ ) (Table 3 ).

Table 3: The level of physical activity according to obesity status of university students

\begin{tabular}{|c|c|c|c|c|c|}
\hline \multirow[t]{2}{*}{ Variables } & \multicolumn{2}{|r|}{ Male $(n=90)$} & \multicolumn{2}{|r|}{ Famale $(\mathrm{n}=130)$} & \multirow[b]{2}{*}{$\begin{array}{c}\text { Total } \\
(\mathrm{n}=220)\end{array}$} \\
\hline & $\begin{array}{l}\text { Normal } \\
(\mathrm{n}=62)\end{array}$ & $\begin{array}{l}\text { Overweight \& Obesity } \\
(\mathrm{n}=28)\end{array}$ & $\begin{array}{l}\text { Normal } \\
(\mathrm{n}=80)\end{array}$ & $\begin{array}{c}\text { Overweight \& Obesity } \\
(\mathrm{n}=50)\end{array}$ & \\
\hline \multicolumn{6}{|c|}{$\begin{array}{l}\text { At least } 30 \text { minutes of physical activity } \\
\text { per day (days/week) }\end{array}$} \\
\hline No & 13(20.9) & $6(21.5)$ & 15(18.7) & $13(26.0)^{\star *}$ & $47(21.4)$ \\
\hline $1-2$ & $18(29.0)$ & $8(28.5)$ & $25(31.3)$ & $11(22.0)$ & $62(28.2)$ \\
\hline $3-4$ & $17(27.4)$ & $6(21.5)$ & $18(22.5)$ & $16(32.0)$ & $57(25.9)$ \\
\hline $5-6$ & $8(12.9)$ & $5(17.9)$ & $14(17.5)$ & $6(12.0)$ & $33(15.0)$ \\
\hline 7 & $6(9.7)$ & $3(10.7)$ & $8(10.0)$ & $4(8.0)$ & $21(9.5)$ \\
\hline \multicolumn{6}{|c|}{ Walking or riding a bicycle (days/week) } \\
\hline No & $9(14.6)$ & $11(39.2)^{*}$ & $24(30.0)$ & $14(28.0)^{*}$ & $58(26.4)$ \\
\hline $1-2$ & $10(16.2)$ & $4(14.3)$ & $10(12.5)$ & $7(14.0)$ & $31(14.1)$ \\
\hline $3-4$ & $15(24.1$ & $3(10.7)$ & $9(11.2)$ & $8(16.0)$ & $35(16.0)$ \\
\hline $5-6$ & $17(27.4)$ & $5(17.9)$ & $20(25.0)$ & $11(22.0)$ & $53(24.0)$ \\
\hline 7 & $11(17.7)$ & $5(17.9)$ & $17(21.3)$ & $10(20.0)$ & $43(19.5)$ \\
\hline \multicolumn{6}{|c|}{$\begin{array}{l}\text { Time spent walking during weekdays } \\
\text { (hours/day) }\end{array}$} \\
\hline$<30 \mathrm{~min}$ & $12(19.3)$ & $6(21.5)$ & $19(23.7)$ & $15(30.0)^{\star \star}$ & $52(23.6)$ \\
\hline $30 \min \leq<1$ hour & $27(43.6)$ & $14(50.0)$ & $24(30.0)$ & $20(40.0)$ & $85(38.6)$ \\
\hline 1 hour $\leq<2$ hours & $10(16.2)$ & $6(21.5)$ & $20(25.0)$ & $8(16.0)$ & $44(20.0)$ \\
\hline 2 hours $\leq$ & $13(20.9)$ & $2(7.0)$ & $17(21.3)$ & $7(14.0)$ & $39(17.8)$ \\
\hline \multicolumn{6}{|c|}{$\begin{array}{l}\text { Time spent walking during the week- } \\
\text { end (hours/day) }\end{array}$} \\
\hline$<30 \mathrm{~min}$ & 11(17.7) & $7(25.1)$ & $18(22.5)$ & $16(32.0)^{\star \star}$ & $52(23.7)$ \\
\hline $30 \min \leq<1$ hour & $28(45.2)$ & $15(53.5)$ & $25(31.3)$ & $19(38.0)$ & $87(39.5)$ \\
\hline 1 hour $\leq<2$ hours & $10(16.2)$ & $5(17.9)$ & $21(26.2)$ & $9(18.0)$ & $44(20.0)$ \\
\hline 2 hours $\leq$ & $13(20.9)$ & $1(3.5)$ & $17(21.3)$ & $6(12.0)$ & $37(16.8)$ \\
\hline \multicolumn{6}{|c|}{$\begin{array}{l}\text { Sedentary activity during weekdays } \\
\text { (hours/day) }\end{array}$} \\
\hline$<3$ & $42(67.7)$ & $22(78.5)^{* *}$ & $55(68.7)$ & $36(72.0)^{\star *}$ & $155(70.5)$ \\
\hline $3 \leq$ & $20(32.3)$ & $6(21.5)$ & $25(31.3)$ & $14(28.0)$ & $65(29.5)$ \\
\hline \multicolumn{6}{|c|}{$\begin{array}{l}\text { Sedentary activity during the weekend } \\
\text { (hours/day) }\end{array}$} \\
\hline$<3$ & $46(74.1)$ & $20(71.5)^{* *}$ & $53(66.2)$ & $38(76.0)^{\star \star}$ & $157(71.3)$ \\
\hline $3 \leq$ & $16(25.9)$ & $8(28.5)$ & 27(33.8) & $12(24.0)$ & $63(28.7)$ \\
\hline \multicolumn{6}{|c|}{$\begin{array}{l}\text { Number of days for exercise (times/ } \\
\text { week) }\end{array}$} \\
\hline No & $8(12.9)$ & $3(10.7)$ & $12(15.0)$ & $8(16.0)^{* *}$ & $31(14.1)$ \\
\hline 1 & $14(22.6)$ & $6(21.5)$ & $18(22.5)$ & $11(22.0)$ & $49(22.3)$ \\
\hline 2 & $18(29.0)$ & $9(32.1)$ & $24(30.0)$ & $15(30.0)$ & $66(30.0)$ \\
\hline $3 \leq$ & $22(35.5)$ & $10(35.7)$ & $26(32.5)$ & $16(32.0)$ & $74(33.6)$ \\
\hline
\end{tabular}

There was no significant difference between the OW and NW groups in both genders regarding nutrition knowledge. OW was found to have a total self-efficacy score $(\mathrm{P}<0.01)$ and a physical activity self-efficacy score $(\mathrm{P}<0.01)$ in women. The
OW women had significantly lower physical activity self-efficacy scores than NW women $(\mathrm{P}<0.01)$. However, there was no significant difference in eating habit between self-efficacy score between OW and NW groups in both genders (Table 4). 
Tablo 4: Nutritional knowledge and self-efficacy levels according to obesity status in university students

\begin{tabular}{|c|c|c|c|c|c|}
\hline \multirow{2}{*}{ Variables } & \multicolumn{2}{|r|}{ Male $(n=90)$} & \multicolumn{2}{|r|}{ Famale $(\mathrm{n}=130)$} & \multirow[b]{2}{*}{$\begin{array}{c}\text { Total } \\
(\mathrm{n}=220)\end{array}$} \\
\hline & $\begin{array}{l}\text { Normal } \\
(\mathrm{n}=62)\end{array}$ & $\begin{array}{l}\text { Overweight \& Obesity } \\
(\mathrm{n}=28)\end{array}$ & $\begin{array}{l}\text { Normal } \\
(\mathrm{n}=80)\end{array}$ & $\begin{array}{c}\text { Overweight \& Obesity } \\
(\mathrm{n}=50)\end{array}$ & \\
\hline Nutrition Knowledge & & & & & \\
\hline General nutrition knowledge score ${ }^{1)}$ & $4.2 \pm 0.7$ & $3.8 \pm 0.6$ & $4.2 \pm 0.7$ & $3.8 \pm 0.6$ & $4.0 \pm 0.7$ \\
\hline Obesity knowledge score & $3.2 \pm 0.7$ & $3.1 \pm 0.6$ & $3.4 \pm 0.8$ & $3.3 \pm 0.7$ & $3.3 \pm 0.7$ \\
\hline $\begin{array}{l}\text { Nutrition knowledge total score } \\
\text { Self-efficacy }\end{array}$ & $7.8 \pm 1.4$ & $7,9 \pm 1.2$ & $7.8 \pm 1.4$ & $7.9 \pm 1.2$ & $7.9 \pm 1.3$ \\
\hline Eating self-efficacy score & $17.2 \pm 2.8$ & $18.2 \pm 2.9$ & $18.4 \pm 3.0$ & $19.1 \pm 3.1$ & $18.2 \pm 2.9$ \\
\hline Physical activity self-efficacy score & $12.8 \pm 2.1$ & $11.2 \pm 2.7^{\star *}$ & $12.7 \pm 2.2$ & $11.1 \pm 2.7^{\star *}$ & $11.9 \pm 2.4$ \\
\hline Self-efficacy total score & $31.7 \pm 4.1$ & $31.7 \pm 4.2$ & $31.8 \pm 4.1$ & $30.7 \pm 3.7^{\star *}$ & $31.4 \pm 4.0$ \\
\hline
\end{tabular}

Mean $\pm \mathrm{SD},{ }^{* *} \mathrm{P}<0.01$

\section{Discussion}

The aim of this study is to examine the eating habits, physical activities, nutrition knowledge and self-sufficiency of university students and to investigate whether these characteristics differ according to obesity status. Gender is significantly different according to obesity status; In the OW group, the rate of famale $(64.1 \%)$ was higher than that of the NW group (56.3\%). In a study conducted (Yahia et al., 2008), the majority of university students show normal weight. Normal weight women $(76.8 \%)$ and men (49\%) are overweight and obese than males. In the United States, $35 \%$ of the college students are reported to be overweight or obese $(\mathrm{BMI} \geq 25)$ (Lowry et al., 2000).

According to our research results, eating habits according to obesity status of university students were lower than the NW group of both sexes. While eating out does not differ from obesity in men, OW consumes less women than women. The eating rate was significantly higher in the OW group than in the NW group in both boys and girls. In a study (Sakata et al., 2001), it was found that the proportion of individuals with regular eating patterns in young Japanese was low. Skipping breakfast is associated with low nutritional status and the risk of cardiovascular disease. It has been reported that adequate breakfast habits may contribute to the development and further development of obesity (Ortega et al., 1996). These findings support our findings.

This study shows that; physical activity variables in women and men were significantly different between OW and NW groups. The percentage of those who said that they did not use hiking or cycling on weekends was higher in male OW and female OW groups. On weekends, men and women participated in physical activity less than 3 hours a day, and on weekends NW group participated in physical activity for at least 30 minutes a day. In a study conducted, the nutrition and physical activity habits and obesity cases of the university students were investigated, Only $8.5 \%$ of girl students and only $28.1 \%$ of male students had sufficient physical activity level (Arslan et al., 2016). Similarly, in the previous study (Song, 2011) obese children were reported to have negative attitudes and are less likely to participate in physical activity than normal weight children.

This study revealed that there was no significant difference between the OW and NW groups in both genders regarding nutrition knowledge. The OW women had significantly lower physical activity self-efficacy scores than NW women. However, there was no significant difference in eating habit between self-efficacy score between OW and NW groups in both genders. This finding suggests the importance of self-sufficiency that explains obesity or healthy behavior. Studies of self-efficacy in obese children (Ahn et al., 2011; Franklin et al., 2006) have found that children have difficulties with psychosocial adaptation and that they are able to perform or perceive their physical activity more negatively with increasing obesity.

As a result, it was determined that OW group students participated less in physical activity than NW students in this study. Healthy eating habits such as breakfast eating and the size of an adequate meal seemed to be less preferred in OW group students and especially in women. Nutritional information does not show any significant difference between OW and NW groups, while physical activity self-efficacy is lower in OW group than NW group. For this reason, physical education programs for the prevention of obesity in children should attach importance to increasing the confidence in performing exercise or physical activity. Physical education programs should focus on providing practical tips 
for increasing physical activity and changing eating behavior. In addition, they should include adequate methods of body image, body satisfaction and weight control. In addition, university students are at risk because of lack of nutrition knowledge, psycho-social and economic reasons, TV and peer interaction and similar reasons. In this context it is important to give information to young people, families and trainers about this issue and raise awareness.

\section{References}

Ahn HS, Chung KM, Jeon J (2011). The effect of BMI and physical ability on self-efficacy, quality of life, and self-esteem in overweight and obese children. Korean $J$ Health Psychol; 16:537-55.

Arslan SA, Daşkapan A, Çakır B (2016). Specification of nutritional and physical activity habits of university students. TAF Prev Med Bull; 15:(3), 171-180.

Brown JE, Isaacs JS, Krinke UB, Lechtenberg E, Murtaugh MA, Sharbaugh C, Splett PL, Stang J, Wooldridge NH (2011). Nutrition through the Life Cycle. 4th ed. Belmont (CA): Wadsworth.

Caspersen, C.J., Pereira, M.A., Curran, K.M (2000). Changes in Physical Activity Patterns in the United States, By Sex and Cross-Sectional Age. Medicine and Science in Sports and Exercise. 32. pp.1601-1609.

Centers for Disease Control and Prevention (US) (2007). State and Local Youth Risk Behavior Survey. Clifton road Atlanta (GA): Centers for Disease Control and Prevention.

Cho YG, Song HR, Kim KA, Kang JH, Song YH, Yun HJ, Kim HS (2009). Effect of a school-based intervention for overweight children "fitness class" performed on elementary schools located in Seoul. Korean J Obes;18: 146-57.

Choi HJ, Seo JS (2003). Nutrient intakes and obesity-related factors of obese children and the effect of nutrition education program. Korean J Community Nutr; 8:47784.

Franklin J, Denyer G, Steinbeck KS, Caterson ID, Hill AJ (2006). Obesity and risk of low self-esteem: a statewide survey of Australian children. Pediatrics; 118:2481-7.

Guthold R, Cowan MJ, Autenrieth CS, Kann L, Riley LM (2010). Physical activity and sedentary behavior among schoolchildren: a 34-country comparison. I Pediatr; 157:43-49.

Hatfield DP, Chomitz VR, Chui KK, Sacheck JM, Economos CD (2015). Demographic, physiologic, and psychosocial correlates of physical activity in structured exercise and sports among low-income, overweight children. J Nutr Educ Behav; 47:452-458.

Kang JH (2009). Relationship between physical activi- ty and psychological factors in obese children [doctor's thesis]. Seoul: Korea National Sport University

Keihner AJ, Meigs R, Sugerman S, Backman D, Garbolino T, Mitchell P (2011). The power play! Campaign's school idea \& resource kits improve determinants of fruit and vegetable intake and physical activity among fourth- and fifth-grade children. J Nutr Educ Behav;43: S122-9.

Ko SY, Kim KW (2010). Nutrition label use, self-efficacy, snacking and eating behavior of middle school students in Kyunggi area. Korean J Community Nutr; 15:513-24.

Lee SY, Ha SA, Seo JS, Sohn CM, Park HR, Kim KW (2014). Eating habits and eating behaviors by family dinner frequency in the lower-grade elementary school students. Nutr Res Pract; 8:679-87.

Lowry R, Galuska DA, Fulton JE, Wechsler H, Kann L, Collins JL Jan (2000). Physical activity, food choice, and weight management goals and practices among US college students. Am J Prev Med; 18:18-27.

Na SY, Ko SY, Eom SH, Kim KW (2010). Intakes and beliefs of vegetables and fruits, self-efficacy, nutrition knowledge, eating behavior of elementary school students in Kyunggi area. Korean J Community Nutr; 15:329-41.

Seong AH, Lee1 SY, Kim KA, Seo JS, Sohn CM, Park HR and Kim KW (2016). Eating habits, physical activity, nutrition knowledge, and self-efficacy by obesity status in upper-grade elementary school students. Nutrition Research and Practice;10(6):597-605

Song JH (2011). The relationships between physical education attitudes and levels of physical activity in overweight and normal weight elementary school students. Korean J Elem Phys Educ;17: 99-109.

WHO: Growth reference data for 5-19 years: WHO Reference; 2007. http://www. who. int/ growthref /en.

WMADH (2000). World Medical Association Declaration of Helsinki: Ethical Principles for Medical Research Involving Human Subjects. Journal of the American Medical Association. 284. pp. 3043-3045.

Yahia N, Achkar A, Abdallah A, Rizk S (2008). Eating habits and obesity among Lebanese university students. Nutrition Journal, 7(32) 1-6.

Yu SH, Song Y, Park M, Kim SH, Shin S, Joung H (2014). Relationship between adhering to dietary guidelines and the risk of obesity in Korean children. Nutr Res Pract;8:705-12.

Corresponding author: Okt. Pervin TOPTAŞ DEMİRCí ${ }^{1}$ ${ }^{1}$ Mersin University Department of Tourism Animation, Mersin/Turkey

Email: *pervindemirci36@hotmail.com

Work Phone: +90 (0324) 3610126

Fax: +90 (0324) 3610127 